\title{
Nop9 recognizes structured and single-stranded RNA elements of preribosomal RNA
}

\author{
JUN ZHANG,${ }^{1,2}$ TAKAMASA TERAMOTO, ${ }^{1,3}$ CHEN OIU, ${ }^{1}$ ROBERT N. WINE, ${ }^{1}$ LAUREN E. GONZALEZ, ${ }^{1}$ \\ SUSAN J. BASERGA, ${ }^{4,5,6}$ and TRACI M. TANAKA HALL' \\ ${ }^{1}$ Epigenetics and Stem Cell Biology Laboratory, National Institute of Environmental Health Sciences, National Institutes of Health, \\ Research Triangle Park, North Carolina 27709, USA \\ ${ }^{2}$ Department of Chemistry, University of Alabama at Birmingham, Birmingham, Alabama 35294, USA \\ ${ }^{3}$ Department of Bioscience and Biotechnology, Faculty of Agriculture, Kyushu University, Fukuoka 819-0395, Japan \\ ${ }^{4}$ Department of Genetics, Yale University School of Medicine, New Haven, Connecticut 06520, USA \\ ${ }^{5}$ Department of Therapeutic Radiology, Yale University School of Medicine, New Haven, Connecticut 06520, USA \\ ${ }^{6}$ Department of Molecular Biophysics and Biochemistry, Yale University School of Medicine, New Haven, Connecticut 06520, USA
}

\begin{abstract}
Nop9 is an essential factor in the processing of preribosomal RNA. Its absence in yeast is lethal, and defects in the human ortholog are associated with breast cancer, autoimmunity, and learning/language impairment. PUF family RNA-binding proteins are best known for sequence-specific RNA recognition, and most contain eight $\alpha$-helical repeats that bind to the RNA bases of single-stranded RNA. Nop9 is an unusual member of this family in that it contains eleven repeats and recognizes both RNA structure and sequence. Here we report a crystal structure of Saccharomyces cerevisiae Nop9 in complex with its target RNA within the 20S preribosomal RNA. This structure reveals that Nop9 brings together a carboxy-terminal module recognizing the $5^{\prime}$ single-stranded region of the RNA and a bifunctional amino-terminal module recognizing the central double-stranded stem region. We further show that the $3^{\prime}$ single-stranded region of the 20S target RNA adds sequence-independent binding energy to the RNA-Nop9 interaction. Both the amino- and carboxy-terminal modules retain the characteristic sequence-specific recognition of PUF proteins, but the amino-terminal module has also evolved a distinct interface, which allows Nop9 to recognize either single-stranded RNA sequences or RNAs with a combination of single-stranded and structured elements.
\end{abstract}

Keywords: Nop9; RNA; PUF protein; ribosome biogenesis

\section{INTRODUCTION}

RNA-binding proteins must select their intended targets with the appropriate fidelity to regulate specific networks of RNAs. To do so, different modules may be combined in a single protein to bring together their distinct RNA recognition capabilities and diversify the RNA sequences and structures that are bound by the whole protein versus the individual domains. Many RNA-binding proteins contain multiple copies of prominent RNA-binding domains, such as RNA recognition motifs and K-homology domains (Lunde et al. 2007). Domains contribute their individual RNA recognition properties to produce an overall specificity for the multidomain protein. The overall specificity may be additive with domains connected by flexible linkers like beads on a string and able to achieve many different ar-

Corresponding author: hall4@niehs.nih.gov

Article is online at http://www.rnajournal.org/cgi/doi/10.1261/rna. 075416.120 . rangements. Quite often the domains are interdependent, and the specificity of the multidomain protein relies on restricted relative positions of the individual domains as they bind to their target RNAs.

Pumilio/fem-3 Binding Factor (PUF) proteins are a relatively small but unique class of modular RNA-binding proteins. PUF proteins comprise $\alpha$-helical Pumilio (PUM) repeats (Barker et al. 1992; Macdonald 1992; Zamore et al. 1997; Zhang et al. 1997). Classical PUF proteins are formed from eight PUM repeats, and they bind sequence specifically to single-stranded RNA. Each PUM repeat comprises three $\alpha$ helices, and the second helix contains three amino acid side chains called the tripartite recognition motif (TRM) that select a specific RNA base (Edwards

C) 2020 Zhang et al. This article is distributed exclusively by the RNA Society for the first 12 months after the full-issue publication date (see http://rnajournal.cshlp.org/site/misc/terms.xhtml). After 12 months, it is available under a Creative Commons License (Attribution-NonCommercial 4.0 International), as described at http:// creativecommons.org/licenses/by-nc/4.0/. 
et al. 2001; Wang et al. 2001, 2002; Campbell et al. 2014). The eight PUM repeats of a classical PUF protein are interdependent and arrange to form a crescent-shaped PUM homology domain (PUM-HD) with single-stranded RNA binding on the concave surface. The overall conformation of a PUM-HD correlates with the length of RNA sequence that it binds, with flatter surfaces selecting longer RNA sequences. Interaction with different length sequences is often accomplished by a two-handed mechanism: one set of PUM repeats recognizes a conserved 5' UGUA sequence while another set of PUM repeats recognizes a $3^{\prime}$ element with variability interspersed (Wang et al. 2002, 2009; Miller et al. 2008; Zhu et al. 2009; Lu and Hall 2011; Qiu et al. 2012, 2019; Valley et al. 2012; Wilinski et al. 2015; Bhat et al. 2019).
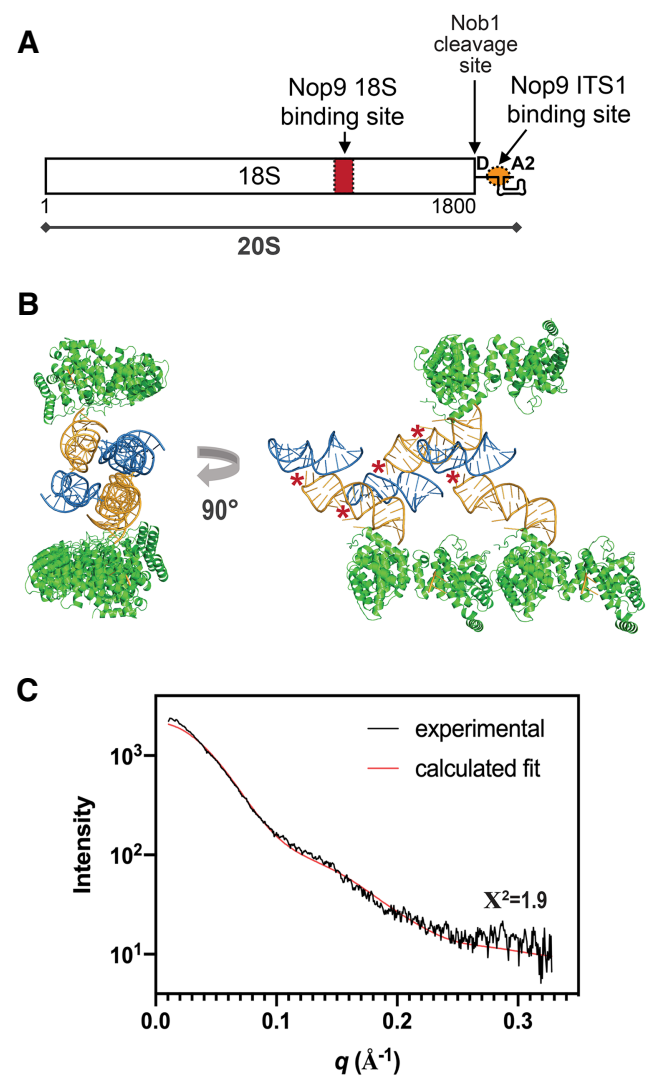

FIGURE 1. Crystallization of a complex of Nop9 with ITS1 RNA. (A) Schematic drawing of the $20 \mathrm{~S}$ pre-rRNA. Nop9 binds to a singlestranded RNA sequence in the 18S rRNA (red, nucleotides 11401150 in S. cerevisiae) and to a structured RNA site within the ITS1 fragment between sites $D$ and $A 2$ (orange, focused at nucleotides 13-19/ 204-212 in S. cerevisiae). Nob1 cleaves the 20S pre-rRNA at site D to produce the mature 18S rRNA. (B) Crystal packing arrangement of Nop9 and ITS1 RNA. Each asymmetric unit contains one Nop9/ITS1 complex (green Nop9 and orange ITS1) plus a second ITS1 RNA (blue) that bridges between two Nop9/ITS1 complexes. The GAAA tetraloop/tetraloop receptor interactions are indicated by red asterisks. (C) Superimposed experimental scattering curve for a Nop9: ITS1 RNA complex (black) and a calculated scattering curve for the crystal structure of Nop9/ITS1 RNA (red).
The PUF protein family also includes two groups of proteins that contain PUM repeats but are structurally and functionally different from the classical PUF proteins that recognize single-stranded RNA sequences (Qiu et al. 2014; Zhang et al. 2016a). Both Nop9 and Puf-A (also known as mammalian PUM3, an ortholog of yeast Puf6) recognize structured RNA and participate in preribosomal RNA processing (Thomson et al. 2007; Li et al. 2009; Tafforeau et al. 2013; Qiu et al. 2014; Zhang et al. 2016a; Wang and Ye 2017). Ribosome biogenesis is an ordered process that requires hundreds of factors to assemble ribosomal RNAs (rRNAs) and ribosomal proteins into the large ribonucleoprotein complex for protein synthesis (Woolford and Baserga 2013; de la Cruz et al. 2015; Henras et al. 2015; Lafontaine 2015). The pre-rRNA undergoes multiple cleavage and trimming steps to remove the external and internal transcribed spacers and generate the mature rRNAs. Nop9 and Puf-A proteins are critical for small and large ribosomal subunit assembly, respectively (Thomson et al. 2007; Li et al. 2009; Tafforeau et al. 2013; Qiu et al. 2014; Zhang et al. 2016a; Wang and Ye 2017). Alterations in expression level or sequence of human NOP9 and Puf-A are associated with breast cancer, autoimmunity, and learning/language impairment, indicating the importance of these atypical PUF proteins for human health (Brickner et al. 2001; Akatsuka et al. 2003; Kuo et al. 2009; Fan et al. 2013; Turpeinen et al. 2013; Nudel et al. 2014).

Nop9 is essential for maturation of the $18 \mathrm{~S}$ small ribosomal subunit rRNA (Thomson et al. 2007; Li et al. 2009). Depletion of Nop9 in yeast is lethal, as it abolishes synthesis of the small ribosomal subunit (Thomson et al. 2007; Li et al. 2009; Chaker-Margot et al. 2015; Zhang et al. 2016b). During ribosome biogenesis the small ribosomal subunit $20 \mathrm{~S}$ pre-rRNA is produced in the nucleus, released to the nucleoplasm, and then exported to the cytoplasm where cleavage at site D by the endonuclease Nob1 removes internal transcribed spacer 1 (ITS1) sequences to produce the mature 18S rRNA (Fig. 1A; Fatica et al. 2003; Lamanna and Karbstein 2009; Pertschy et al. 2009; Strunk et al. 2011; Lebaron et al. 2012; Chaker-Margot et al. 2015). Although cleavage of the 20S pre-rRNA occurs in the cytoplasm, Nob1 associates with the 20S pre-RNA in the nucleolus and therefore Nob1 nuclease activity must be prevented. Nop9 joins the assembling preribosome before Nob1. It interacts with a single-stranded RNA sequence within the 18S rRNA (nucleotides 1140-1150 in the $S$. cerevisiae 18S rRNA, Fig. 1A), a potential initial binding site as the pre-rRNA is transcribed (Wang and Ye 2017). It has been suggested that Nop9 binding may assist in folding of the central pseudoknot region of the rRNA, which is located at this Nop9 interaction site. Nop9 also recognizes a stem-loop and $5^{\prime}$ and $3^{\prime}$ flanking regions in ITS1 of the 20S pre-rRNA (focused at nucleotides 13-19/ 204-212 in S. cerevisiae ITS1, Fig. 1A), which follows the 
18S rRNA sequence (Thomson et al. 2007; Zhang et al. 2016a). The Nop9 binding site within ITS1 is near the Nob1 cleavage site that separates the 18S rRNA from the ITS1 region; furthermore, we have shown that Nop9 impedes Nob1 cleavage to prevent premature cleavage of the $20 \mathrm{~S}$ pre-rRNA by Nob1 in the nucleolus (Zhang et al. 2016a).

Unlike other PUF protein families, we found that Nop9 has the ability to bind to both single-stranded RNA sequences and structured elements. We have previously determined a crystal structure of S. cerevisiae Nop9 in the absence of RNA that revealed a C-shaped protein comprising 11 PUM repeats (Zhang et al. 2016a). A small-angle X-ray scattering (SAXS) model of the Nop9-ITS1 stemloop RNA indicated that Nop9 uses a new mode of RNA recognition for PUM repeat proteins. However, this lowresolution model could not provide the details of protein-RNA recognition. Here we present a crystal structure of Nop9 in complex with ITS1 RNA. The structure of the binary complex showed the details of how Nop9 recognizes the base of the ITS1 stem-loop using its amino-terminal PUM repeats, consistent with our previous SAXS model. In addition, the structure revealed that Nop9 uses its carboxy-terminal PUM repeats to recognize single-stranded RNA bases. This dual RNA recognition mode illustrates the evolution of PUM repeat proteins to combine recognition of sequence and structure. Moreover, we find that Nop9 adjusts the angle between the amino- and carboxy-terminal repeat modules to bind to RNAs using a two-handed mechanism like that of classical PUF proteins.

\section{RESULTS}

\section{Crystal structure of a Nop9-ITS1 protein-RNA complex}

We determined a crystal structure of $S$. cerevisiae Nop9 in complex with ITS1 RNA at $3.0 \AA$ resolution (Table 1). Obtaining crystals of the Nop9/ITS1 complex was challenging, as demonstrated by the more than 10,000 crystallization trials with protein and RNA variants that did not yield diffracting crystals. To favor crystallization, we engineered the ITS1 RNA with guidance from existing data. Our previous small-angle $X$-ray scattering (SAXS) model of the Nop9/ITS1 complex showed that the distal end of the ITS1 stem-loop does not interact with Nop9 (Zhang et al. 2016a). Moreover, we had shown that truncation or mutation of the distal stem sequence did not affect binding affinity. Therefore, we substituted the distal end of the ITS1 stem-loop with a GAAA tetraloop and a tetraloop receptor (Coonrod et al. 2012). This method had been established to promote crystal packing of RNA molecules via the interaction of the tetraloop on one RNA molecule with the tetraloop receptor on another molecule. In the case of the Nop9-ITS1 stem-loop RNA complex, the engineered in-
TABLE 1. X-ray data collection and refinement statistics

\begin{tabular}{|c|c|}
\hline & Nop9-RNA \\
\hline \multicolumn{2}{|l|}{ Data collection } \\
\hline Space group & $\mathrm{P} 2{ }_{1} 2_{1} 2_{1}$ \\
\hline \multicolumn{2}{|l|}{ Cell dimensions } \\
\hline$a, b, c(\AA)$ & $71.9,119.5,142.1$ \\
\hline$\alpha, \beta, \gamma\left(^{\circ}\right)$ & $90,90,90$ \\
\hline Resolution (Å) & $50-3.02(3.13-3.02)^{a}$ \\
\hline$R_{\text {merge }}$ & $0.047(0.75)$ \\
\hline$|/ \sigma|$ & $22.43(3.27)$ \\
\hline Completeness (\%) & $99.1(94.3)$ \\
\hline Redundancy & $14.4(15.0)$ \\
\hline Wilson B-factor & 102.8 \\
\hline \multicolumn{2}{|l|}{ Refinement } \\
\hline Resolution (Å) & $35-3.02$ \\
\hline No. reflections & 24,488 \\
\hline$R_{\text {work }} / R_{\text {free }}$ & $19.9 \% / 23.2 \%$ \\
\hline No. atoms & 5913 \\
\hline Macromolecules & 5889 \\
\hline Solvent & 24 \\
\hline \multicolumn{2}{|l|}{ B-factors } \\
\hline Macromolecules & 105.2 \\
\hline Solvent & 108.0 \\
\hline \multicolumn{2}{|l|}{ R.m.s. deviations } \\
\hline Bond lengths ( $(\AA)$ & 0.003 \\
\hline Bond angles $\left({ }^{\circ}\right)$ & 0.583 \\
\hline
\end{tabular}

aValues in parentheses are for the highest resolution shell, 3.13-3.02 A.

teraction between ITS1 RNA molecules would favor crystallization but should not interfere with protein-RNA interactions. We also engineered the protein, deleting residues 164-175, which are in a loop that was disordered in our previous structure of the Nop9 protein alone (Zhang et al. 2016a), and substituting a short linker. As expected, neither the RNA nor the protein engineering disrupted the ability of Nop9 to bind to ITS1 RNA (Table 2). On the contrary, the deletion of residues 164-175 increased the affinity of Nop9 for the RNA. These strategies allowed us to obtain diffracting crystals of a Nop9/ITS1 complex and to determine the crystal structure by molecular replacement.

The crystals of the Nop9/ITS1 complex contained two molecules of ITS1 RNA and one molecule of Nop9 protein per asymmetric unit. One molecule of ITS1 RNA was bound to Nop9 (orange in Fig. 1B), while a second bridging ITS1 molecule (blue in Fig. 1B) formed GAAA tetraloop-receptor interactions with the ITS1 RNA in two Nop9/ITS1 complexes (red asterisks in Fig. 1B). The engineered GAAA tetraloop-receptor interactions mediated lattice formation by creating a $\mathrm{P} 2{ }_{1}$ screw axis. We confirmed that these lattice interactions did not appear to distort the Nop9/ITS1 complex relative to the structure in solution by comparing a calculated scattering curve for 
TABLE 2. Nop9 binding affinities for ITS1 RNA

\begin{tabular}{|c|c|c|c|}
\hline Protein variant & RNA variant ${ }^{a}$ & $K_{\mathrm{d}}(\mathrm{nM})$ & $K_{\text {rel }}$ \\
\hline Nop9 46-645 & ITS1 7-38, 184-206 & $11.8 \pm 0.4$ & 1 \\
\hline Nop9 46-645 & $\begin{array}{l}\text { ITS1 7-25 (tetraloop/ } \\
\text { receptor) 199-206 }\end{array}$ & $15.3 \pm 0.5$ & 1.3 \\
\hline $\begin{array}{r}\text { Nop9 46-645 } \\
(\Delta 164-175)\end{array}$ & ITS1 7-38, 184-206 & $1.6 \pm 0.1$ & 0.14 \\
\hline Nop9 46-645 & $\begin{array}{l}\text { Synthetic ITS1 7-32, } \\
\text { 192-206 }\end{array}$ & $14.0 \pm 1.9$ & 1.2 \\
\hline
\end{tabular}

an vitro transcribed RNAs contain a $5^{\prime} G G$ preceding the U7 nucleotide, which is absent from the synthetic RNA.

our crystal structure with the SAXS data reported previously for a Nop9/ITS1 complex (Fig. 1C; Zhang et al. 2016a). We determined the $\chi^{2}$ for the fit was 1.9 , which is similar to the fit of our previous rigid-body docked model of the complex to the same data ( $\chi^{2}$ of 2.0). In addition, RNARNA interactions in the crystal packing did not occlude the Nop9 concave surface, where the putative RNA recognition TRMs reside. We therefore conclude that the crystal structure of the Nop9/ITS1 complex is consistent with the SAXS solution structure. We present the details of interaction between Nop9 and a single ITS1 molecule and refer to it hereafter as the Nop9/ITS1 complex.

\section{Nop9 interacts with the base of the ITS1 RNA duplex}

The Nop9/ITS1 crystal structure revealed interactions between Nop9 and ITS1 RNA in two regions. Nop9 binds to the proximal base pairs of the ITS1 RNA stem-loop near amino-terminal PUM repeats R1 and R2 and also binds to single-stranded RNA bases using repeats R8R11 (Fig. 2). The overall conformation of Nop9 changes with RNA binding. We compared the structure of Nop9 in complex with ITS1 with our previous structure of apo Nop9 (PDB ID: 5SVD) and found that ITS1 binding resulted in a more closed Nop9 conformation (Fig. 3A). This closure reduced the distance between the amino- and carboxyterminal repeats from 30 to $20 \AA$ (distance between the $\mathrm{C} \alpha$ atoms of Ala75 and lle600). Conformational changes resulted from differences at the repeat R4-R5 and R7-R8 junctions, where we had previously noted the protein structure twisted (Zhang et al. 2016a). Closure upon RNA binding is also observed when Nop9 is bound to a single-stranded RNA sequence from the 18S rRNA (Wang and Ye 2017). Surprisingly, binding to either ITS1 or the 18S rRNA sequence induced a similar closed Nop9 conformation (Fig. 3B, RMSD $0.76 \AA$ over 500 C $\alpha$ atoms). The plant ortholog of Nop9, Arabidopsis thaliana APUM23, also binds to the single-stranded 18S rRNA sequence (Bao et al. 2017). APUM23 has an overall structure that is quite similar to Nop9, but it is in a more open conformation when bound to single-stranded RNA (Fig. 3C). APUM23 uses an insertion in its third PUM repeat to interact with and position the RNA. This insertion could also help to maintain the open conformation, as it interacts with APUM23 repeats R3-R8 (Fig. 3C). Although Repeat R3 of Nop9 also contains an insertion, it was disordered or absent in all crystal structures. Nevertheless, the lack of sequence conservation between this R3 insertion in Nop9 with the R3 insertion in APUM23 suggests that this function is not retained in Nop9 (Bao et al. 2017).

Nop9 recognizes the nucleotides and structure at the base of the ITS1 duplex region (Fig. 2). Residues near the amino-terminal ends of the second $\alpha$-helices of Repeats R1 and R2 interact with base pairs in the RNA minor groove (Fig. 4A). K140 is within hydrogen bonding distance of the base and the $2^{\prime} \mathrm{OH}$ group of $\mathrm{U} 18$ and the $\mathrm{O}^{\prime}$ atom in the ribose ring of $\mathrm{G} 19$, and $\mathrm{Q} 104$ is positioned similarly to interact with the base and $2^{\prime} \mathrm{OH}$ group of G19. PUM repeats in other PUF proteins contain similar conserved residues near the amino-terminal ends of the second RNA recognition helices that stack with one another and form a ridge. In human Pumilio1 and other classical PUF proteins, this ridge positions the ribose groups of single-stranded RNA rather than recognizing bases as it does in Nop9 (Fig. 4B). In our crystal structure of the atypical PUF protein, Puf-A, we observed residues at the equivalent positions interacting with the major groove of a doublestranded DNA (Fig. 4C; Qiu et al. 2014). The conservation and positioning of these residues between Nop9 and
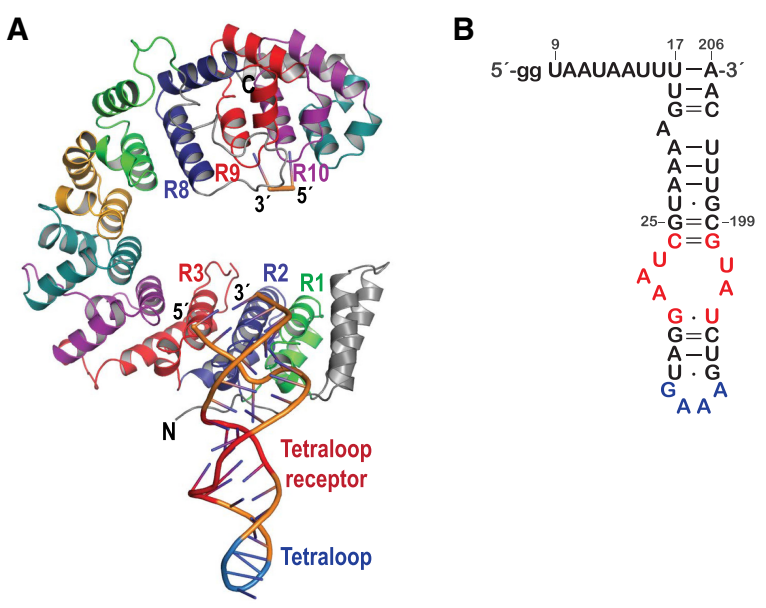

FIGURE 2. Crystal structure of Nop9 in complex with ITS1 RNA. (A) Ribbon diagram of Nop9 in complex with ITS1 RNA. The Nop9 PUM repeats R1-R11 are colored sequentially and amino- and carboxy-terminal capping helices are shown in gray. Repeats R1-R3 interact at the base of the ITS1 stem-loop and repeats R8-R11 interact with single-stranded RNA. (B) ITS1 RNA stem-loop with engineered tetraloop and tetraloop receptor. Sequence and secondary structure of ITS1 RNA with a tetraloop receptor (red) and tetraloop (blue) added to facilitate crystallization. Two guanine nucleotides were added at the $5^{\prime}$ end to promote transcription and are shown in lowercase. 
A

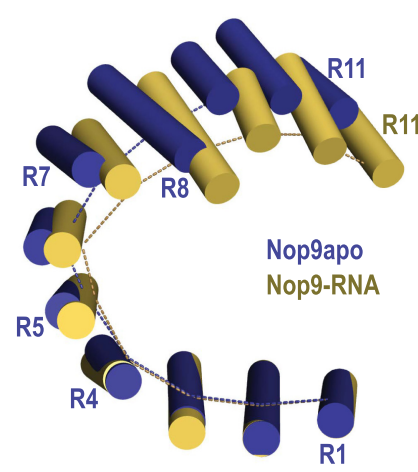

C

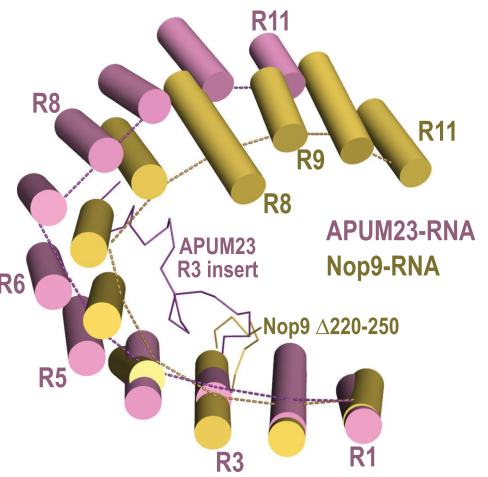

B

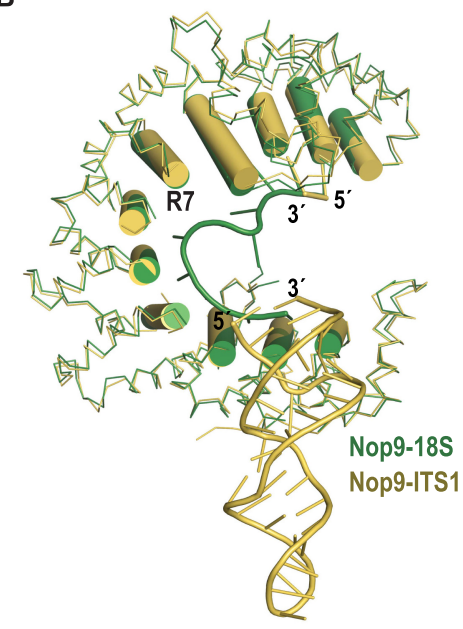

FIGURE 3. The overall conformation of Nop9 closes upon RNA binding. (A) The inner helices lining the concave face of Nop9 alone (blue, PDB ID: 5SVD) or bound to ITS1 RNA (yellow) are shown as cylinders. Repeats R1-R4 were superimposed. Dotted lines connect the $\mathrm{C} \alpha$ atoms of the TRM residues that would typically form stacking interactions with RNA bases. (B) Nop9 assumes the same overall conformation in complex with ITS1 RNA or single-stranded 18S rRNA. The crystal structures of Nop9 in complex with ITS1 RNA (yellow) and 18S rRNA (green, PDB ID: 5WTY) are superimposed, and the inner helices lining the concave face of Nop9 are shown as cylinders. (C) A. thaliana APUM23 maintains a more open conformation when bound to singlestranded 18S rRNA. The inner helices lining the concave face of APUM23 (pink, PDB ID: 5WZH) and Nop9 (yellow) are shown as cylinders. Repeats R1-R3 were superimposed. Dotted lines connect the $\mathrm{C} \alpha$ atoms of the TRM residues that would typically form stacking interactions with RNA bases. A C $\alpha$ trace for an insertion (residues 234-257) that occurs between $\alpha$-helices 2 and 3 in repeat R3 of APUM23 is shown. Residues 258-270 that are also part of the R3 insert are disordered in the APUM23 crystal structure. An equivalent insertion between $\alpha$-helices 2 and 3 in repeat R3 of Nop9 including residues 220-250 was present but not visible in our structure (labeled $\Delta 220-250$ ), and it was deleted from Nop9 in the crystal structure of the Nop9-18S rRNA complex.

Puf-A suggests that Puf-A might also recognize the nucleotides of structured RNA.

Nop9 possesses a well-conserved amino-terminal peptide that interacts with the first $\alpha$-helices of repeats R1 and R2, and within this peptide, the exposed aromatic ring of F52 stacks with the unpaired A2O base (Fig. 4D). This interaction appears to be non-sequence specific, which is consistent with our previous results demonstrating that substituting the $\mathrm{AU}$-rich sequence in this region with a GC-rich sequence had little effect on in vitro binding affinity (Zhang et al. 2016a). Recognition of the A20 structural feature and the base-paired sequence further supports our finding that the base of the ITS1 duplex region is vital for Nop9 binding.

\section{Nop9 recognizes the $5^{\prime}$ single- stranded region of ITS1 RNA}

In addition to interaction by repeats R1 and R2 with the base of the ITS1 duplex, we observed electron density near the RNA-binding TRMs of repeats R8-R10 indicating that Nop9 bound to single-stranded RNA (Fig. $5 A)$. The only single-stranded region within the crystallized RNA was the $5^{\prime}$ region of the ITS1 RNA, nucleotides 9-16 (Fig. 2B). The shape and size of the electron density suggested that the two $5^{\prime}$ nt were consecutive purines and partial electron density was present for a third nucleotide. If we placed a model of three nucleotides into this density, the shortest distance between the $3^{\prime}$ end of the singlestranded RNA and the $5^{\prime}$ end of the duplex region (U17) was $28 \AA$. Phosphate-to-phosphate distances within the RNA backbone of A-form RNA are $\sim 6.0 \AA$. Therefore, at least 4-5 nt are needed to span the distance between the two ends. The simplest interpretation was to assign the two $5^{\prime}$ nucleotides as A10-A11, and we did not fit a third nucleotide into the partial density, as there were no instances of three consecutive purines in the $5^{\prime}$ region of the crystallized ITS1 (Fig. 2B). We considered several other possibilities. The single-stranded RNA could belong to an ITS1 molecule other than the one whose duplex region is bound to repeats $\mathrm{R} 1$ and $\mathrm{R} 2$. However, the nearest ITS1 in the lattice is $56 \AA$ away, making this option unlikely. Alternatively, G-G-U9, including the two guanines that were added upstream of U9 to induce in vitro transcription (Fig. 2B), could fit the density. Nevertheless, upstream guanines do not appear to contribute to single-stranded RNA recognition, as a synthetic RNA beginning with the natural U7-U8 without a $5^{\prime}$ G-G bound to Nop9 with similar affinity as in vitro transcribed ITS1 RNA bearing the 5' G-G (14.0 nM vs. 11.8 $\mathrm{nM}$, Table 2). Finally, repeats R8-R11 could bind to an RNA sequence with three nonconsecutive purines, $R-R-$ $X-R$, with a nucleotide $X$ flipped away from the RNA-binding helices of Nop9, as has been observed for other PUF proteins (Miller et al. 2008; Wang et al. 2009; Wilinski et al. 2015). Regardless of the exact assignment, repeats R8 to R11 appear to engage several $5^{\prime} \mathrm{nt}$, which is 
A
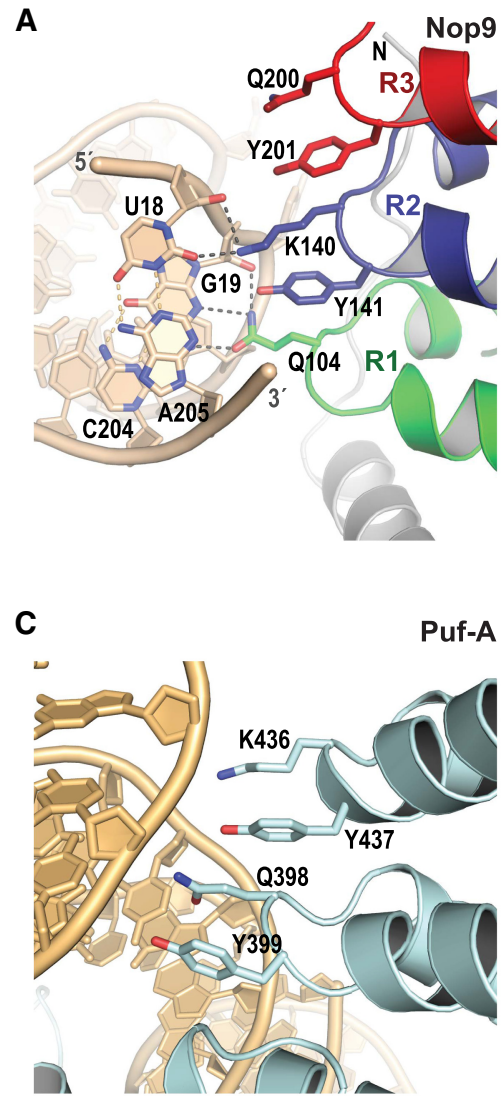

B
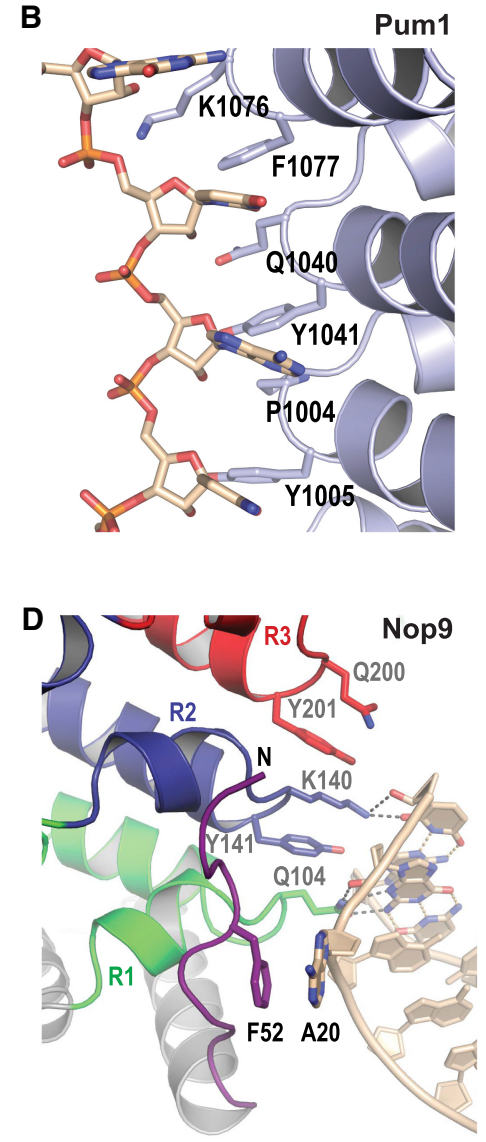

FIGURE 4. Nop9 interacts with nucleotides at the base of the ITS1 stem-loop. (A) Nop9 uses amino acid side chains in the loops between the first and second $\alpha$ helices in repeats R1-R3 to bind to nucleotides in the minor groove of ITS1 RNA. Dashed lines indicate hydrogen bonds. (B) Human Pumilio1 protein (PDB ID: 3QOP) uses equivalent amino acid side chains in its PUM repeats to form van der Waals interactions with the ribose groups of single-stranded RNA. (C) Human Puf-A protein (PDB ID: 4WZW) directs equivalent amino acid side chains toward the major groove of dsDNA. (D) Nop9 uses an amino-terminal extension (purple) to interact with nucleotide A20 in ITS1 RNA. The Nop9-RNA complex is reoriented in A and D relative to Figure $2 A$ in order to provide an unobstructed view of the protein-RNA interactions. The Pumilio1 and Puf-A complexes are oriented similarly to Nop9 in A for ease of comparison.

either purine base. Nop9 repeat R8 is divergent in amino acid sequence with a weakly conserved TRM (Zhang et al. 2016a) and a long loop preceding the RNA interaction helix. Arg485, which is in repeat R8 but not its TRM, is positioned to form a stacking interaction with the third nucleotide in the $5^{\prime}$ ITS1 RNA (Fig. 5A), similar to its interaction with $A 1142$ and $A 1143$ of the 18S rRNA (Fig. 5B). Glu492 in the repeat R8 TRM binds to $18 \mathrm{~S}$ A1142 (Fig. 5B), and it is in position to contact the third nucleotide of the 5' ITS1 RNA (Fig. 5A). Repeat R7 completely lacks a conserved TRM (Zhang et al. 2016a), and its inability to recognize RNA results in a break in the 1 repeat: 1 base recognition pattern for both the ITS1 and 18S RNAs (Fig. 3B). We conclude that Nop9 repeats R8-R11 form a module for recognition of $5^{\prime}$ single-stranded purine sequences in target RNA motifs.

\section{The $3^{\prime}$ end of ITS1 contributes sequence-independent Nop9 binding affinity}

Due to optimization of the RNA for crystallization, the RNA in our Nop9/ ITS1 complex lacked the $3^{\prime}$ singlestranded region of the ITS1 fragment (nucleotides 207-212). However, we had shown previously that this $3^{\prime}$ region does contribute to Nop9/ITS1 binding affinity (Zhang et al. 2016a). The presence of the $3^{\prime}$ single-stranded RNA increased affinity fivefold,

consistent with our previous binding assays demonstrating the importance of this region of the ITS1 RNA (Zhang et al. 2016a). Nop9 repeats R8-R10 also recognize the purinerich 5' GGA sequence of the 18S rRNA element (Wang and Ye 2017), suggesting that these PUM repeats selectively bind single-stranded purine-rich sequences in both target RNAs.

The 5' nucleotides in ITS1 are bound by repeats R8-R11 (Fig. 5A), similar to the "anti-parallel" recognition mode of classical PUF proteins binding to their single-stranded RNA targets. Repeats R11, R10, and R9 use the same side chains to interact with the $A 10$ and $A 11$ purines in ITS1 as had been shown to interact with G1140 and G1141 in the 18S rRNA (Fig. 5B; Wang and Ye 2017). The TRMs in Nop9 repeats R9 and R10 along with Gln604 and Asp608 in R11 appear capable of recognizing from $11.8 \pm 0.4 \mathrm{nM}$ to $2.4 \pm 0.15 \mathrm{nM}$ (Tables 2,3 ). In the absence of structural information, we investigated whether the sequence of the $3^{\prime}$ end of ITS1 influenced interaction with Nop9 by carrying out binding assays with RNA variants. We mutated each of the nucleotides from 207 to 212 and found that substitutions in this region did not dramatically perturb Nop9 binding (Table 3). Therefore, we conclude that the $3^{\prime}$ single-stranded region contributes to Nop9 binding affinity in a sequence-independent manner.

\section{DISCUSSION}

Our crystal structure of a Nop9/ITS1 complex provides a detailed understanding of Nop9's ability to combine modules for sequence and structural recognition to bind to the 


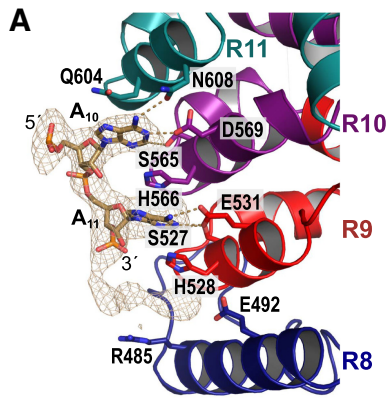

Nop9/ITS1 RNA

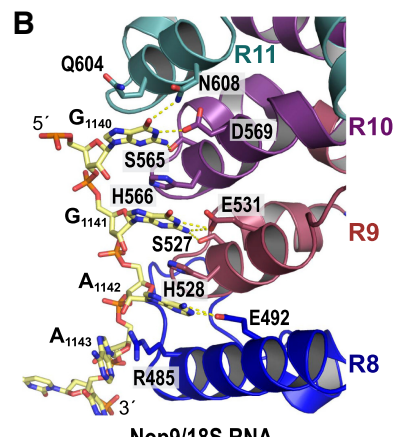

Nop9/18S RNA
FIGURE 5. Nop9 repeats R8-R11 interact with single-stranded RNA. (A) Interaction between Nop9 repeats R8-R11 and the ITS1 RNA. Electron density indicates single-stranded ITS1 RNA is bound to Nop9 repeats R8-R11. A simulated annealing $F_{o}-F_{c}$ electron density omit map contoured at $3 \sigma$ is superimposed on the ITS1 RNA. (B) Interaction between Nop9 repeats R8-R11 and the 18S rRNA (yellow, PDB ID: 5WTY). The Nop9-RNA complexes in this figure are reoriented relative to Figure $2 \mathrm{~A}$ in order to provide an unobstructed view of the protein-RNA interactions.

ITS1 stem-loop RNA (Fig. 6A). This mechanism to combine amino- and carboxy-terminal modules is reminiscent of the two-handed mechanism for single-stranded RNA sequence recognition by classical PUF proteins (Wilinski et al. 2015). The Nop9 bifunctional amino-terminal PUM repeats form one module/hand that can recognize either a single-stranded RNA sequence (18S) or a structured duplex (ITS1). Repeats R1-R5 recognize the sequence of single-stranded $18 \mathrm{~S}$ rRNA primarily using conserved TRM side chains in the second $\alpha$ helices of each repeat. In addition, repeats R1-R3 can recognize duplex RNA using conserved residues in an amino-terminal peptide extension and at the amino-termini of the second $\alpha$ helices. This amino-terminal repeat module has evolved two distinct surfaces for RNA recognition.

The Nop9 carboxy-terminal repeats form a second module/hand that recognizes purine-rich single-stranded RNA using classical PUF protein interactions. Nop9 adapts when binding to either single-stranded or stem-loop
RNA by changing its overall curvature. A hinge point is located between PUM repeats R7 and R8 (Fig. 6A). This flexibility enables repositioning of the carboxy-terminal single-stranded RNA binding module relative to the amino-terminal bifunctional module, and we speculate that different relative positions of the amino- and carboxy-terminal modules allow Nop9 to bind to a range of RNA sequences/structures. For instance, Nop9 could bind to RNAs with different length linkers between a purine-rich element bound by the carboxy-terminal module and a single-stranded or stem-loop motif bound by the amino-terminal module (Fig. 6B).

Although Nop9 has not been identified in any structures of preribosomes likely due to its transient interactions (Barandun et al. 2017; Heuer et al. 2017; Sun et al. 2017; Ameismeier et al. 2018; Scaiola et al. 2018; Cheng et al. 2019; Hunziker et al. 2019), we illustrate the location of Nop9 by placing our crystal structure following the $5^{\prime}$ end of ITS1 in a recent cryo-electron microscopy (cryo-EM) structure of a human late pre-40S ribosome (Fig. 7; Ameismeier et al. 2018). Nop9 binds to ITS1 near the Nob1 cleavage site and inhibits premature processing in the nucleolus (Thomson et al. 2007; Zhang et al. 2016a). Nop9 binds to elements in ITS1 downstream from the binding site for Pno1, which blocks Nob1 cleavage in the cytoplasm (Turowski et al. 2014; Heuer et al. 2017; Johnson et al. 2017; Parker et al. 2019). It appears that both Nop9 and Pno1 could bind simultaneously (Fig. 7), allowing the handoff of Nob1 inhibition from Nop9 in the nucleolus to Pno1 in the cytoplasm. The other known binding site for Nop9 is at a critically important junction in pre-rRNA folding. The single-stranded binding site within the $18 \mathrm{~S}$ rRNA (Fig. 7) includes nucleotides at the interface of two structural regions of the mature rRNA: the central domain and the $3^{\prime}$ major domain (Wang and Ye 2017). The $5^{\prime}$ nucleotides form part of the central pseudoknot and the $3^{\prime}$ nucleotides form one strand of helix H28. We propose that Nop9 is important for the timing of formation of these RNA structures, as its dissociation would be required to free the RNA for base-pairing. This is consistent with recent studies that

TABLE 3. Binding affinity enhancement by the $3^{\prime}$ sequence of ITS1 is sequence independent

\begin{tabular}{|c|c|c|c|c|}
\hline Protein & RNA variant & $3^{\prime}$ sequence & $K_{\mathrm{d}}(\mathrm{nM})$ & $K_{\text {rel }}$ \\
\hline Nop9 46-645 & ITS1 7-38, 184-212 & UACAAC & $2.4 \pm 0.15$ & 1 \\
\hline Nop9 46-645 & U207A & AACAAC & $2.6 \pm 0.1$ & 1.1 \\
\hline Nop9 46-645 & A208U & UUCAAC & $1.8 \pm 0.1$ & 0.75 \\
\hline Nop9 46-645 & C209G & UAGAAC & $4.4 \pm 0.8$ & 1.8 \\
\hline Nop9 46-645 & C209A & UAAAAC & $2.6 \pm 0.2$ & 1.1 \\
\hline Nop9 46-645 & C209U & UAUAAC & $2.5 \pm 0.3$ & 1.04 \\
\hline Nop9 46-645 & $\mathrm{A} 210 \mathrm{U}, \mathrm{A} 211 \mathrm{U}$ & UACUUC & $2.1 \pm 0.3$ & 0.9 \\
\hline Nop9 46-645 & $\mathrm{C} 212 \mathrm{G}$ & UACAAG & $2.9 \pm 0.6$ & 1.2 \\
\hline
\end{tabular}

Nucleotides in the $3^{\prime}$ sequence that were mutated are shown in boldface. 
A

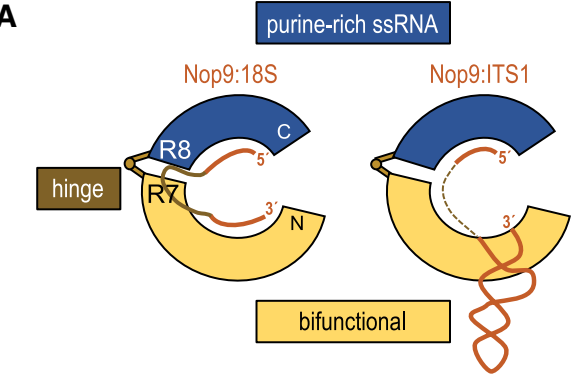

B

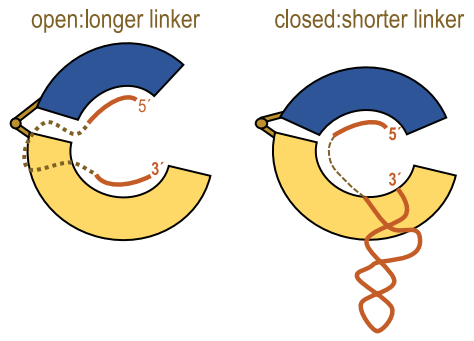

FIGURE 6. A model for RNA interaction by the amino- and carboxyterminal RNA recognition modules of Nop9. (A) A bifunctional aminoterminal module of Nop9 (yellow) binds to single-stranded or structured RNA while a carboxy-terminal module (blue) binds to purinerich single-stranded RNA permitting recognition of both $18 \mathrm{~S}$ and ITS1 RNAs. (B) A hinge region between the amino- and carboxy-terminal modules may adjust the conformation of Nop9 to allow binding to additional RNAs with recognition elements separated by different linker lengths.

indicate that parts of the $3^{\prime}$ domain assemble into the $5^{\prime}$ ETS structure before the central and $5^{\prime}$ domains are incorporated (Cheng et al. 2019). Nop9 with binding sites in both regions is positioned to play a role in ordering these processes. We can also envision that as the pre-20S rRNA is transcribed and undergoes structural changes upon ribosome maturation, it provides other potential transient binding sites for Nop9, combining 5' purine-rich elements with downstream single-stranded or structural elements, that remain to be uncovered.

\section{MATERIALS AND METHODS}

\section{Nop9 expression and purification}

We expressed Nop9 (residues 46-645) using the PSMT3 SUMO fusion protein expression vector (kindly provided by Dr. Christopher Lima, Memorial Sloan Kettering Cancer Center). We used site-directed mutagenesis PCR with corresponding primers to create a construct, Nop $9^{\Delta 164-175}$, encoding Nop9 with a Ser-Gly-Ser linker replacing residues 164-175. Nop9 (residues 46-645) and Nop9 ${ }^{\Delta 164-175}$ were expressed and purified as described previously (Zhang et al. 2016a). Briefly, amino-terminal His 6 -SUMO-tagged Nop9 proteins were expressed at $22^{\circ} \mathrm{C}$ overnight in E. coli BL21-CodonPlus (DE3) in the presence of $0.4 \mathrm{mM}$ IPTG, which was added when the $\mathrm{OD}_{600}$ reached 0.6. Cell pellets were resuspended in sonication buffer (25 mM HEPES pH 7.5, $1 \mathrm{M}$ $\mathrm{NaCl}, 1 \mathrm{mM}$ TCEP, and $25 \mathrm{mM}$ imidazole) plus $1 \mathrm{mg} / \mathrm{mL}$ lysozyme and lysed by sonication, followed by centrifugation to remove cell debris. The supernatant was applied to $5 \mathrm{~mL}$ of HisPur Ni-NTA resin (Thermo Scientific), washed with $200 \mathrm{~mL}$ sonication buffer, and eluted with $25 \mathrm{mM}$ HEPES pH 7.5, $500 \mathrm{mM} \mathrm{NaCl}, 1 \mathrm{mM}$ TCEP, and $500 \mathrm{mM}$ imidazole. The SUMO-tagged proteins were cleaved overnight with $2 \mu \mathrm{g} / \mathrm{mL}$ of Ulp 1 at $4^{\circ} \mathrm{C}$. The cleaved protein sample was diluted fivefold using $20 \mathrm{mM} \mathrm{HEPES} \mathrm{pH}$ 7.5, $20 \mathrm{mM} \mathrm{NaCl}$, and $1 \mathrm{mM}$ TCEP and loaded onto a $5 \mathrm{~mL}$ HiTrap Heparin column (GE Healthcare). The sample was eluted with a linear gradient from 0 to $2 \mathrm{M} \mathrm{NaCl}$ in $20 \mathrm{mM}$ HEPES pH 7.5 and $1 \mathrm{mM}$ TCEP. Nop9 eluted from the Heparin column at $\sim 600 \mathrm{mM}$ $\mathrm{NaCl}$ and was further purified using a HiLoad 16/60 Superdex 200 column (GE Healthcare), equilibrated with 25 mM HEPES $\mathrm{pH} 7.5,500 \mathrm{mM} \mathrm{NaCl}$, and $1 \mathrm{mM}$ TCEP. The identities of the proteins were confirmed by mass spectrometry, and the purities were $>95 \%$ based on SDS-PAGE.

\section{RNA preparation}

The template DNA for in vitro transcription of an ITS1 RNA with a tetraloop and tetraloop receptor to facilitate crystallization was purchased from Eurofins MWG Operon with the coding strand sequence shown in Figure 2B. The T7 promoter sequence (GAAATTAATACGACTCACTATA) was used to initiate in vitro transcription using T7 RNA polymerase, and two 5' guanine nucleotides were included to promote transcription. To increase the homogeneity of the $3^{\prime}$ end of the product RNA, we added two $2^{\prime}$-O-methylguanines at the $5^{\prime}$ end of the template strand (Kao et al. 1999). In vitro transcription reactions were incubated at $37^{\circ} \mathrm{C}$ overnight in $100 \mathrm{mM}$ Tris- $\mathrm{HCl} \mathrm{pH} \mathrm{8.0,20} \mathrm{mM} \mathrm{MgCl}$, $1 \mathrm{mM}$ TCEP, $2 \mathrm{mM}$ spermidine, 3\% (w/v) PEG 8000, 0.01\% (v/v) Triton X-100, 4 mM NTPs, 2 units of inorganic pyrophosphatase,

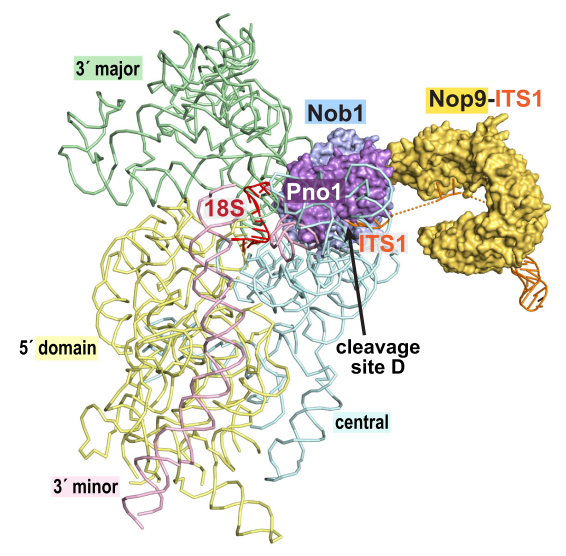

FIGURE 7. Model of Nop9 binding sites in the eukaryotic pre-40S ribosome. A cryo-EM model of the pre-rRNA in a human late pre-40S ribosome (PDB ID: 6G18) is shown with the proteins Nob1 (light blue) and Pno1 (purple). The crystal structure of yeast Nop9 (yellow) in complex with ITS1 RNA was placed adjacent to the $3^{\prime}$ end of the pre-rRNA, which includes four nucleotides of ITS1 (orange). A dotted line of $24 \AA$ connects the $3^{\prime}$ end of the pre-rRNA and the first nucleotide bound to Nop9. The Nop9 binding site in the 18S rRNA is red. Proteins are shown as surface representations, and the structural domains are colored: $5^{\prime}$ domain, yellow; central domain, light cyan; $3^{\prime}$ major domain, green; and $3^{\prime}$ minor domain, pink. 
$0.6 \mu \mathrm{M}$ dsDNA template, and $0.06 \mathrm{mg} / \mathrm{mL}$ T7 RNA polymerase. In vitro transcription products were purified by $15 \%$ polyacrylamide gel electrophoresis $(30 \times 40 \times 1.6 \mathrm{~mm})$ in the presence of $8 \mathrm{M}$ urea and $1 \times$ TBE. After a $1 \mathrm{~h}$ prerun to warm the gel to $50^{\circ} \mathrm{C}$, RNA samples were resolved under constant power of 80 watts for $10 \mathrm{~h}$, during which target RNAs migrated about three quarters of the gel length. RNA was eluted from the excised slices of gel containing target RNAs using a Whatman Elutrap system. Purified RNAs were diluted to $5 \mu \mathrm{M}$ and incubated at $90^{\circ} \mathrm{C}$ for $2 \mathrm{~min}$, followed by a snap-cooling step on ice to refold the RNA. The homogeneity of refolded RNA was confirmed by single bands on $10 \%$ polyacrylamide native TBE gels (Invitrogen). RNA secondary structures were predicted using Mfold (Zuker 2003). The graphic of the RNA secondary structure in Figure 2B was prepared using VARNA (Darty et al. 2009) and edited with Adobe Illustrator, as needed.

\section{Protein crystallization and structure determination}

We crystallized Nop9 ${ }^{\Delta 164-175}$ (residues 46-163; 176-645) in complex with ITS1 RNA (9-25; 199-206) with a tetraloop and tetraloop receptor (Fig. 2B). Initial crystals were obtained by hanging drop vapor diffusion at $22^{\circ} \mathrm{C}$ with a crystallization solution containing 18\% (w/v) PEG 3350, $0.2 \mathrm{M}$ ammonium citrate and $0.1 \mathrm{M}$ MES $\mathrm{pH}$ 6.75. Crystals were improved by iterative microseeding. The crystallization solution was supplemented with $10 \%(\mathrm{v} / \mathrm{v})$ ethylene glycol as a cryo-protectant.

X-ray diffraction data were collected at beamline 22-ID of the Advanced Photon Source (APS) at $100 \mathrm{~K}$ with a wavelength of $1.000 \AA$ A. The data were processed using HKL2000 (Otwinowski and Minor 1997). Phases were determined by molecular replacement using the coordinates of apo Nop9 (PDB ID: 5SVD). Due to the conformational change of Nop9 induced by RNA binding, two fragments of Nop9 separated at residue 331 between repeats R4 and R5 were used as search models for molecular replacement. The RNA chains were manually built in Coot (Emsley et al. 2010). Iterative refinement and model building using Phenix.Refine (Adams et al. 2010) and Coot yielded final R and free $R$ factors of $19.9 \%$ and $23.2 \%$, respectively. Over $95 \%$ of dihedral angles are in favored regions of the Ramachandran plot, and only $0.74 \%$ are Ramachandran plot outliers.

\section{Electrophoretic mobility shift assays}

RNAs were labeled at the $5^{\prime}$ end with ${ }^{32} \mathrm{P}-\gamma$-ATP (PerkinElmer Life Science) by T4 polynucleotide kinase for $1 \mathrm{~h}$ at $37^{\circ} \mathrm{C}$. Unincorporated ${ }^{32} \mathrm{P}-\gamma$-ATP was removed using Illustra MicroSpin G-25 columns. Radiolabeled RNAs ( $<50$ pM) were incubated with protein samples at $4^{\circ} \mathrm{C}$ for $40 \mathrm{~min}$ in $20 \mathrm{mM}$ HEPES pH 7.5, $150 \mathrm{mM} \mathrm{NaCl}, 0.02 \%$ (v/v) Tween-20, and $1 \mathrm{mM}$ TCEP. The samples were resolved on $10 \%$ polyacrylamide native TBE gels at constant voltage $(150 \mathrm{~V})$ with $1 \times$ TBE buffer at $4^{\circ} \mathrm{C}$ for $30 \mathrm{~min}$. The gels were dried and exposed overnight to storage phosphor screens. The phosphor screens were scanned on a Molecular Dynamics Typhoon Phosphorlmager, and band intensities were quantified with ImageQuant 5.2. The data were fit using the Hill equation with GraphPad Prism 6. EMSAs were performed with three technical replicates, and mean $K_{d}$ 's and standard error of the mean are reported.

\section{DATA DEPOSITION}

Atomic coordinates and structure factors for the reported crystal structure have been deposited with the Protein Data Bank under accession number 6WPI.

\section{ACKNOWLEDGMENTS}

We thank L. Pedersen and the staff of the Southeast Regional Collaborative Access Team beamlines for assistance with X-ray data collection. We thank J. Williams of the NIEHS Mass Spectrometry Research and Support Group for mass spectrometric analysis, and the NIEHS NMR Group for advice and feedback regarding experimental design. We are grateful to our colleagues, H. Wang and R. Stanley, for critical comments on the manuscript. This work was supported in part by the Intramural Research Program of the National Institutes of Health, National Institute of Environmental Health Sciences (1ZIA50165 to T.M.T. $\mathrm{H}$.) and the National Institute of General Medical Sciences (R35GM131687 to S.J.B.). The Advanced Photon Source used for this study is supported by the US Department of Energy, Office of Science, Office of Basic Energy Sciences, under contract no. W-31-109-Eng-38.

Author contributions: J.Z., C.Q., T.T., and T.M.T.H. designed research; J.Z., T.T., R.W., C.Q., and L.E.G performed research; J.Z., T.T., R.W., C.Q., L.E.G., S.J.B., and T.M.T.H. analyzed data; and all authors contributed to the writing and editing of the manuscript.

Received March 18, 2020; accepted April 29, 2020.

\section{REFERENCES}

Adams PD, Afonine PV, Bunkoczi G, Chen VB, Davis IW, Echols N, Headd JJ, Hung LW, Kapral GJ, Grosse-Kunstleve RW, et al. 2010. PHENIX: a comprehensive Python-based system for macromolecular structure solution. Acta Crystallogr D Biol Crystallogr 66: 213-221. doi:10.1107/S0907444909052925

Akatsuka Y, Warren EH, Gooley TA, Brickner AG, Lin MT, Hansen JA, Martin PJ, Madtes DK, Engelhard VH, Takahashi T, et al. 2003. Disparity for a newly identified minor histocompatibility antigen, HA-8, correlates with acute graft-versus-host disease after haematopoietic stem cell transplantation from an HLA-identical sibling. Br J Haematol 123: 671-675. doi:10.1046/j.1365-2141.2003 .04676.x

Ameismeier M, Cheng J, Berninghausen O, Beckmann R. 2018. Visualizing late states of human $40 \mathrm{~S}$ ribosomal subunit maturation. Nature 558: 249-253. doi:10.1038/s41586-018-0193-0

Bao H, Wang N, Wang C, Jiang Y, Liu J, Xu L, Wu J, Shi Y. 2017. Structural basis for the specific recognition of $18 \mathrm{~S}$ rRNA by APUM23. Nucleic Acids Res 45: 12005-12014. doi:10.1093/nar/ gkx872

Barandun J, Chaker-Margot M, Hunziker M, Molloy KR, Chait BT, Klinge S. 2017. The complete structure of the small-subunit processome. Nat Struct Mol Biol 24: 944-953. doi:10.1038/nsmb.3472

Barker DD, Wang C, Moore J, Dickinson LK, Lehmann R. 1992. Pumilio is essential for function but not for distribution of the Drosophila abdominal determinant Nanos. Genes Dev 6: 2312 2326. doi:10.1101/gad.6.12a.2312

Bhat VD, McCann KL, Wang Y, Fonseca DR, Shukla T, Alexander JC, Qiu C, Wickens M, Lo TW, Hall TMT, et al. 2019. Engineering a 
conserved RNA regulatory protein repurposes its biological function in vivo. elife 8: e43788. doi:10.7554/eLife.43788

Brickner AG, Warren EH, Caldwell JA, Akatsuka Y, Golovina TN, Zarling AL, Shabanowitz J, Eisenlohr LC, Hunt DF, Engelhard VH, et al. 2001. The immunogenicity of a new human minor histocompatibility antigen results from differential antigen processing. J Exp Med 193: 195-206. doi:10.1084/jem.193.2.195

Campbell ZT, Valley CT, Wickens M. 2014. A protein-RNA specificity code enables targeted activation of an endogenous human transcript. Nat Struct Mol Biol 21: 732-738. doi:10.1038/nsmb.2847

Chaker-Margot M, Hunziker M, Barandun J, Dill BD, Klinge S. 2015. Stage-specific assembly events of the 6-MDa small-subunit processome initiate eukaryotic ribosome biogenesis. Nat Struct Mol Biol 22: 920-923. doi:10.1038/nsmb.3111

Cheng J, Bassler J, Fischer P, Lau B, Kellner N, Kunze R, Griesel S, Kallas M, Berninghausen O, Strauss D, et al. 2019. Thermophile $90 \mathrm{~S}$ pre-ribosome structures reveal the reverse order of co-transcriptional 18S rRNA subdomain integration. Mol Cell 75: $1256-$ 1269 e1257. doi:10.1016/j.molcel.2019.06.032

Coonrod LA, Lohman JR, Berglund JA. 2012. Utilizing the GAAA tetraloop/receptor to facilitate crystal packing and determination of the structure of a CUG RNA helix. Biochemistry 51: 8330-8337. doi:10.1021/bi300829w

Darty K, Denise A, Ponty Y. 2009. VARNA: interactive drawing and editing of the RNA secondary structure. Bioinformatics 25: 19741975. doi:10.1093/bioinformatics/btp250

de la Cruz J, Karbstein K, Woolford JL Jr. 2015. Functions of ribosomal proteins in assembly of eukaryotic ribosomes in vivo. Annu Rev Biochem 84: 93-129. doi:10.1146/annurev-biochem-060614033917

Edwards TA, Pyle SE, Wharton RP, Aggarwal AK. 2001. Structure of Pumilio reveals similarity between RNA and peptide binding motifs. Cell 105: 281-289. doi:10.1016/S0092-8674(01)00318-X

Emsley P, Lohkamp B, Scott WG, Cowtan K. 2010. Features and development of Coot. Acta Crystallogr D Biol Crystallogr 66: 486-501. doi:10.1107/S0907444910007493

Fan CC, Lee LY, Yu MY, Tzen CY, Chou C, Chang MS. 2013. Upregulated hPuf-A promotes breast cancer tumorigenesis. Tumour Biol 34: 2557-2564. doi:10.1007/s13277-013-0801-4

Fatica A, Oeffinger M, Dlakic M, Tollervey D. 2003. Nob1p is required for cleavage of the $3^{\prime}$ end of 18S rRNA. Mol Cell Biol 23: 17981807. doi:10.1128/MCB.23.5.1798-1807.2003

Henras AK, Plisson-Chastang C, O'Donohue MF, Chakraborty A, Gleizes PE. 2015. An overview of pre-ribosomal RNA processing in eukaryotes. Wiley Interdiscip Rev RNA 6: 225-242. doi:10 .1002/wrna.1269

Heuer A, Thomson E, Schmidt C, Berninghausen O, Becker T, Hurt E, Beckmann R. 2017. Cryo-EM structure of a late pre-40S ribosomal subunit from Saccharomyces cerevisiae. eLife 6: e30189. doi:10 .7554/eLife.30189

Hunziker M, Barandun J, Buzovetsky O, Steckler C, Molina H, Klinge S. 2019. Conformational switches control early maturation of the eukaryotic small ribosomal subunit. eLife 8: e45185. doi:10.7554/ elife.45185

Johnson MC, Ghalei H, Doxtader KA, Karbstein K, Stroupe ME. 2017. Structural heterogeneity in pre-40S ribosomes. Structure 25: 329340. doi:10.1016/j.str.2016.12.011

Kao C, Zheng M, Rudisser S. 1999. A simple and efficient method to reduce nontemplated nucleotide addition at the $3^{\prime}$ terminus of RNAs transcribed by T7 RNA polymerase. RNA 5: 1268-1272. doi:10.1017/S1355838299991033

Kuo MW, Wang SH, Chang JC, Chang CH, Huang LJ, Lin HH, Yu AL, $\mathrm{Li}$ WH, Yu J. 2009. A novel puf-A gene predicted from evolutionary analysis is involved in the development of eyes and primordial germ-cells. PLOS ONE 4: e4980. doi:10.1371/journal.pone .0004980

Lafontaine DL. 2015. Noncoding RNAs in eukaryotic ribosome biogenesis and function. Nat Struct Mol Biol 22: 11-19. doi:10 $.1038 / \mathrm{nsmb} .2939$

Lamanna AC, Karbstein K. 2009. Nob1 binds the single-stranded cleavage site $D$ at the $3^{\prime}$-end of $18 \mathrm{~S}$ rRNA with its PIN domain. Proc Natl Acad Sci 106: 14259-14264. doi:10.1073/pnas .0905403106

Lebaron S, Schneider C, van Nues RW, Swiatkowska A, Walsh D, Bottcher B, Granneman S, Watkins NJ, Tollervey D. 2012. Proofreading of pre-40S ribosome maturation by a translation initiation factor and 60S subunits. Nat Struct Mol Biol 19: 744-753. doi:10.1038/nsmb.2308

Li Z, Lee I, Moradi E, Hung NJ, Johnson AW, Marcotte EM. 2009. Rational extension of the ribosome biogenesis pathway using network-guided genetics. PLoS Biol 7: e1000213. doi:10.1371/jour nal.pbio. 1000213

Lu G, Hall TMT. 2011. Alternate modes of cognate RNA recognition by human PUMILIO proteins. Structure 19: 361-367. doi:10 .1016/j.str.2010.12.019

Lunde BM, Moore C, Varani G. 2007. RNA-binding proteins: modular design for efficient function. Nat Rev Mol Cell Biol 8: 479-490. doi:10.1038/nrm2178

Macdonald PM. 1992. The Drosophila pumilio gene: an unusually long transcription unit and an unusual protein. Development 114: 221-232.

Miller MT, Higgin JJ, Hall TMT. 2008. Basis of altered RNA-binding specificity by PUF proteins revealed by crystal structures of yeast Puf4p. Nat Struct Mol Biol 15: 397-402. doi:10.1038/nsmb.1390

Nudel R, Simpson NH, Baird G, O'Hare A, Conti-Ramsden G, Bolton PF, Hennessy ER, Consortium SLI, Ring SM, Davey Smith G, et al. 2014. Genome-wide association analyses of child genotype effects and parent-of-origin effects in specific language impairment. Genes Brain Behav 13: 418-429. doi:10.1111/gbb .12127

Otwinowski Z, Minor W. 1997. Processing of x-ray diffraction data collected in oscillation mode. Methods Enzymol 276: 307-326. doi:10.1016/S0076-6879(97)76066-X

Parker MD, Collins JC, Korona B, Ghalei H, Karbstein K. 2019. A kinase-dependent checkpoint prevents escape of immature ribosomes into the translating pool. PLoS Biol 17: e3000329. doi:10 .1371/journal.pbio.3000329

Pertschy B, Schneider C, Gnadig M, Schafer T, Tollervey D, Hurt E. 2009. RNA helicase Prp43 and its co-factor Pfa1 promote 20 to $18 \mathrm{~S}$ rRNA processing catalyzed by the endonuclease Nob1. J Biol Chem 284: 35079-35091. doi:10.1074/jbc.M109.040774

Qiu C, Kershner A, Wang Y, Holley CP, Wilinski D, Keles S, Kimble J, Wickens M, Hall TMT. 2012. Divergence of Pumilio/fem-3 mRNA binding factor (PUF) protein specificity through variations in an RNA-binding pocket. J Biol Chem 287: 6949-6957. doi:10 $.1074 / j b c . M 111.326264$

Qiu C, McCann KL, Wine RN, Baserga SJ, Hall TMT. 2014. A divergent Pumilio repeat protein family for pre-rRNA processing and mRNA localization. Proc Natl Acad Sci 111: 18554-18559. doi:10.1073/ pnas. 1407634112

Qiu C, Bhat VD, Rajeev S, Zhang C, Lasley AE, Wine RN, Campbell ZT, Hall TMT. 2019. A crystal structure of a collaborative RNA regulatory complex reveals mechanisms to refine target specificity. eLife 8: e48968. doi:10.7554/eLife.48968

Scaiola A, Pena C, Weisser M, Bohringer D, Leibundgut M, KlingaufNerurkar P, Gerhardy S, Panse VG, Ban N. 2018. Structure of a eukaryotic cytoplasmic pre-40S ribosomal subunit. EMBO J 37: e98499. doi:10.15252/embj.201798499 
Strunk BS, Loucks CR, Su M, Vashisth H, Cheng S, Schilling J, Brooks CL III, Karbstein K, Skiniotis G. 2011. Ribosome assembly factors prevent premature translation initiation by $40 \mathrm{~S}$ assembly intermediates. Science 333: 1449-1453. doi:10.1126/science .1208245

Sun Q, Zhu X, Qi J, An W, Lan P, Tan D, Chen R, Wang B, Zheng S, Zhang $C$, et al. 2017. Molecular architecture of the $90 \mathrm{~S}$ small subunit pre-ribosome. eLife 6: e22086. doi:10.7554/eLife.22086

Tafforeau L, Zorbas C, Langhendries JL, Mullineux ST, Stamatopoulou V, Mullier R, Wacheul L, Lafontaine DL. 2013. The complexity of human ribosome biogenesis revealed by systematic nucleolar screening of pre-rRNA processing factors. Mol Cell 51: 539-551. doi:10.1016/j.molcel.2013.08.011

Thomson E, Rappsilber J, Tollervey D. 2007. Nop9 is an RNA binding protein present in pre-40S ribosomes and required for $18 \mathrm{~S}$ rRNA synthesis in yeast. RNA 13: 2165-2174. doi:10.1261/rna.747607

Turowski TW, Lebaron S, Zhang E, Peil L, Dudnakova T, Petfalski E, Granneman S, Rappsilber J, Tollervey D. 2014. Rio1 mediates ATP-dependent final maturation of $40 \mathrm{~S}$ ribosomal subunits. Nucleic Acids Res 42: 12189-12199. doi:10.1093/nar/gku878

Turpeinen H, Ojala PJ, Ojala K, Miettinen M, Volin L, Partanen J. 2013. Minor histocompatibility antigens as determinants for graft-versushost disease after allogeneic haematopoietic stem cell transplantation. Int J Immunogenet 40: 495-501. doi:10.1111/iji.12051

Valley CT, Porter DF, Qiu C, Campbell ZT, Hall TMT, Wickens M. 2012. Patterns and plasticity in RNA-protein interactions enable recruitment of multiple proteins through a single site. Proc Natl Acad Sci 109: 6054-6059. doi:10.1073/pnas.1200521109

Wang B, Ye K. 2017. Nop9 binds the central pseudoknot region of $18 \mathrm{~S}$ rRNA. Nucleic Acids Res 45: 3559-3567. doi:10.1093/nar/ gkw1323

Wang X, Zamore PD, Hall TMT. 2001. Crystal structure of a Pumilio homology domain. Mol Cell 7: 855-865. doi:10.1016/S1097-2765 (01)00229-5
Wang X, McLachlan J, Zamore PD, Hall TMT. 2002. Modular recognition of RNA by a human Pumilio-homology domain. Cell 110: $501-$ 512. doi:10.1016/S0092-8674(02)00873-5

Wang Y, Opperman L, Wickens M, Hall TMT. 2009. Structural basis for specific recognition of multiple mRNA targets by a PUF regulatory protein. Proc Natl Acad Sci 106: 20186-20191. doi:10.1073/pnas .0812076106

Wilinski D, Qiu C, Lapointe CP, Nevil M, Campbell ZT, Hall TMT, Wickens M. 2015. RNA regulatory networks diversified through curvature of the PUF protein scaffold. Nat Commun 6: 8213. doi:10.1038/ncomms9213

Woolford JL Jr, Baserga SJ. 2013. Ribosome biogenesis in the yeast Saccharomyces cerevisiae. Genetics 195: 643-681. doi:10.1534/ genetics.113.153197

Zamore PD, Williamson JR, Lehmann R. 1997. The Pumilio protein binds RNA through a conserved domain that defines a new class of RNA-binding proteins. RNA 3: 1421-1433.

Zhang B, Gallegos M, Puoti A, Durkin E, Fields S, Kimble J, Wickens MP. 1997. A conserved RNA-binding protein that regulates sexual fates in the $C$. elegans hermaphrodite germ line. Nature 390: 477-484. doi:10.1038/37297

Zhang J, McCann KL, Qiu C, Gonzalez LE, Baserga SJ, Hall TMT. 2016a. Nop9 is a PUF-like protein that prevents premature cleavage to correctly process pre-18S rRNA. Nat Commun 7: 13085. doi:10.1038/ncomms13085

Zhang L, Wu C, Cai G, Chen S, Ye K. 2016b. Stepwise and dynamic assembly of the earliest precursors of small ribosomal subunits in yeast. Genes Dev 30: 718-732. doi:10.1101/gad.274688.115

Zhu D, Stumpf CR, Krahn JM, Wickens M, Hall TMT. 2009. A 5' cytosine binding pocket in Puf3p specifies regulation of mitochondrial mRNAs. Proc Natl Acad Sci 106: 20192-20197. doi:10.1073/pnas .0812079106

Zuker M. 2003. Mfold web server for nucleic acid folding and hybridization prediction. Nucleic Acids Res 31: 3406-3415. doi:10.1093/ nar/gkg595 

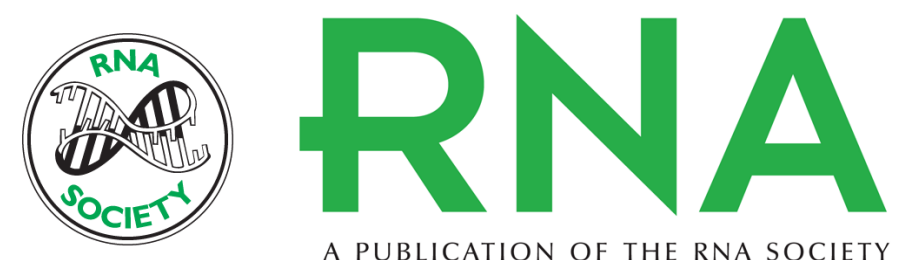

A PUBLICATION OF THE RNA SOCIETY

\title{
Nop9 recognizes structured and single-stranded RNA elements of preribosomal RNA
}

Jun Zhang, Takamasa Teramoto, Chen Quu, et al.

RNA 2020 26: 1049-1059 originally published online May 5, 2020

Access the most recent version at doi:10.1261/rna.075416.120

\begin{abstract}
References This article cites 59 articles, 17 of which can be accessed free at: http://rnajournal.cshlp.org/content/26/8/1049.full.html\#ref-list-1

Creative This article is distributed exclusively by the RNA Society for the first 12 months after the Commons full-issue publication date (see http://rnajournal.cshlp.org/site/misc/terms.xhtml). After 12 License months, it is available under a Creative Commons License (Attribution-NonCommercial 4.0 International), as described at http://creativecommons.org/licenses/by-nc/4.0/.
\end{abstract}

Email Alerting Receive free email alerts when new articles cite this article - sign up in the box at the Service top right corner of the article or click here.

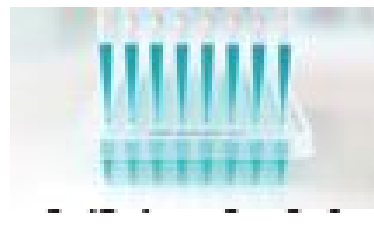

\section{Providing Precise Solutions for} your research.

To subscribe to RNA go to:

http://rnajournal.cshlp.org/subscriptions 